\title{
Effect of Pretreatment With Extract of Origanum vulgare Leaves on Experimental Intestinal Ischemia-Reperfusion Injury in Rats
}

\author{
Omid Azari, ${ }^{1,}{ }^{*}$ Reza Kheirandish, ${ }^{2}$ Hamideh Rohani, ${ }^{3}$ and Saeedeh Shojaeepour ${ }^{4}$ \\ ${ }^{1}$ Department of Clinical Sciences, Faculty of Veterinary Medicine, Shahid Bahonar University of Kerman, Kerman, IR Iran \\ ${ }^{2}$ Department of Pathobiology, Faculty of Veterinary Medicine, Shahid Bahonar University of Kerman, Kerman, IR Iran \\ ${ }^{3}$ Doctor of Veterinary Medicine, Faculty of Veterinary Medicine, Shahid Bahonar University of Kerman, Kerman, IR Iran \\ ${ }^{4}$ Veterinary Pharmacologist, Faculty of Veterinary Medicine, Shiraz University, Shiraz, IR Iran \\ "Corresponding author: Omid Azari, Department of Clinical Sciences, Faculty of Veterinary Medicine, Shahid Bahonar University of Kerman, Kerman, IR Iran. E-mail: \\ omidazari@mail.uk.ac.ir
}

Received 2015 July 8; Accepted 2015 December 11.

\begin{abstract}
Background: Origanum vulgare is used in traditional medicine for antimicrobial, anti-inflammatory and antioxidant activities. Objectives: The present study was designed to investigate the protective effects of $O$. vulgare leaves extract on experimentally induced intestinal ischemia/reperfusion (I/R) injury in rats.

Materials and Methods: In this experimental study, 24 male Wistar albino rats randomly divided into four groups. Group I/R underwent ischemia-reperfusion of the intestine ( 45 minutes of ischemia followed by 1 hour of reperfusion). Treatment groups I and II were given 0 . vulgare extract (200 and $400 \mathrm{ppm}$ ) via oral gavages for 1 week before inducing I/R. Group sham was given normal saline orally without inducing $\mathrm{I} / \mathrm{R}$. After the experiments, the jejunum was removed and the tissues were processed for histomorphometric examination of mucosa.

Results: The treatment with 0 . vulgare extract significantly decreased mucosal damages in the treatment groups compared to group $\mathrm{I} / \mathrm{R}$, while severe mucosal damages were observed in the group $\mathrm{I} / \mathrm{R}$. Also, there was significant difference between treatment groups I and II $(\mathrm{P}=0.054)$. Group sham observed normal intestinal mucosa.

Conclusions: According to the results of current study, administration of $O$. vulgare extract protects the intestinal mucosa from I/R injuries.
\end{abstract}

Keywords: Ischemia-Reperfusion Injury, Intestine, Rat, Origanum vulgare

\section{Background}

Ischemia-reperfusion (I/R) injury of the intestine is an important factor associated with a high morbidity and mortality in both surgical and trauma patients [1]. It is very important in some situations such as the interruption of blood flow to the gut as in abdominal aortic aneurysm surgery, cardiopulmonary bypass, strangulated hernias, neonatal necrotizing enterocolitis and intestinal transplantation [2]. I/R injury of the intestine also occur in septic and hypovolemic shock [3, 4]. Intestinal I/R injury may induce multiple organ dysfunction syndromes (MODS), which is associated with damage of oxygen radicals, energy metabolism and overload of intracellular calcium, leukocyte adhesion and endothelial cell injury [5]. During reperfusion, oxygen reaches the tissue and produces a large amount of reactive oxygen species (ROS), resulting in peroxidation of cell membrane and ultimately apoptosis due to exacerbation of necrosis and triggering of a series of biochemical reactions [5, 6]. Thus many methods have been used to prevent or reduce oxidative stress damage, including the use of low temperature, antioxidants drugs, free radical scavengers for reducing the active oxygen production and ischemic pretreatment [6-9].

Origanum vulgare is part of the Labiatae family [10] and belongs to the Origanum genus which is native to warm temperate environments from Eurasia to the Mediterranean region $[10,11]$. O. vulgare is used in traditional medicine as diuretic, stimulant, antimicrobial, antiinflammatory, antioxidant and anticancer [12]. Many of these activities have been attributed to compounds including, carvacrol, thymol, rosmarinic acid, borneol, organol, ursolic acid, monoterpene hydrocarbons (limonene, terpinene, ocimene, caryophyllene, $\beta$-bisabolene and p-cymene) and monoterpene alcohols (linalool, 4-terpineol) [13-16].

\section{Objectives}

To now date, there is no documented data about the intestinal protective effects of $O$. vulgare in intestinal ischemia reperfusion injury, so the present study was designed to evaluate the effect of ethanolic extract of $O$. vul- 
gare in protection of the intestinal mucosa following experimental intestinal ischemia/reperfusion injury in rats.

\section{Materials and Methods}

\subsection{Plant Material and Extraction Procedure}

In this experimental study, O. vulgare plants were collected at flowering stage from plants growing wildly in Kerman province, Iran. Taxonomic identification of plant materials was confirmed by the agricultural research centre of Shahid Bahonar University of Kerman and voucher specimens were deposited in the Herbarium of the school of pharmacy, Kerman University of Medical Sciences, Kerman, Iran. One gram of dry oregano leaves powder was added to $200 \mathrm{~mL}$ of distilled water and boiled until the volume was reduced to $100 \mathrm{~mL}$. The extract was then stirred at room temperature for 24 hours. Water soluble extracts were obtained following centrifugation at $10,000 \times \mathrm{g}$ for 14 minutes [17].

\subsection{Animals}

Twenty four male Wistar albino rats with weight ranging 200 - 250 g were provided from the animal laboratory of Kerman University of Medical Science, Kerman, Iran. The animals were housed at a temperature of $21-24^{\circ} \mathrm{C}$ in an airconditioned room with a controlled 12 hours light-dark cycle and supplied with standard pellet food and tap water ad libitum. All rats received humane care according to the research ethic committee of the Shahid Bahonar University of Kerman, Iran.

\subsection{Study Design}

The rats were randomly divided into 4 equal groups. In group $I / R$, the rats were treated with normal saline $(1$ $\mathrm{mL} / \mathrm{rat}$ ) for 1 week before surgery operation. On day 8 , the animals were anesthetized by intramuscular injection of xylazine $2 \%$ (10 mg/kg) and ketamine 10\% (90 mg/kg). All operative procedures were performed under aseptic condition by one surgeon. The abdomen was opened by a midline incision and the bowels were partly exteriorized outside the peritoneal cavity to the right side to expose the aorta. The bowels were kept warm by wet gauze with warm normal saline and the animals were kept warm by an overhead heating lamp during surgery. Intestinal ischemia was induced by clamping the aorta with a vascular clamp above the celiac artery. The abdomen was closed and after 45 minutes, the clamp was removed to reperfusion the gut. One hour after reperfusion, the animal's abdomen was reopened and 2 inches of proximal jejunum was removed for microscopic investigation. Finally the animals were killed. In treatment groups I and II, the animals were gavaged with 200 and $400 \mathrm{ppm}(1 \mathrm{~mL} / \mathrm{rat})$ of the ethanolic extract of $O$. vulgare, respectively for one week before surgical operation. On day 8, the animals underwent abdominal operation same as group $\mathrm{I} / \mathrm{R}$ (inducing $\mathrm{I} / \mathrm{R}$ injury by clamping and declamping the abdominal aorta) and jejunum specimens were collected, finally. In group sham, the animals were gavaged daily with normal saline $(1 \mathrm{~mL} / \mathrm{rat})$ same as group I/R. On day 8, the abdomen was opened and the visceral organs were manipulated without applying clamps. The abdomen was closed and then reopened in the same time interval as the other groups and finally the specimens were taken from the proximal jejunum. The intestinal lumen in all groups were immediately cleaned with phosphate buffered saline and the tissues were fixed by injecting 10\% phosphate-buffered formalin through one end of the bowel using a $20 \mathrm{~mL}$ syringe, then intestine was engulfed in $10 \%$ phosphate-buffered formalin. The specimens were further fixed in the same fixative for 48 hours. The samples were embedded in paraffin wax afterwards. Sections in $5 \mu \mathrm{m}$ thickness were stained with hematoxylineosin and examined microscopically.

Microscopic lesions in the intestine were graded according to the scoring system of Chiu et al. Accordingly, the lesions were evaluated as follows: normal intestinal mucosal villi (grade 0 ); villous edema and vascular congestion (grade 1); fragmentation of tips of villi with hemorrhage (grade 2); fragmentation and loss of upper third of villi (grade 3); villi lost but crypts present (grade 4) and complete mucosal necrosis (grade 5) [18].

\subsection{Statistical Analysis}

Obtained data were expressed as median and range for all groups. Scored values were analyzed using nonparametric Mann-Whitney $U$ test due to the small sample size. The SPSS-16 (SPSS Inc., Chicago, IL, USA) was used in order to perform analyses. $\mathrm{P}<0.05$ was considered to be statistically significant.

\section{Results}

Histomorphometrical findings of the sham group revealed normal intestinal mucosa (median 0 , range 0 $0)$, characterized by tall villi with equal thickness and normal crypt (Figure 1A). Significant increase in histomorphometric scores was noted in $\mathrm{I} / \mathrm{R}$ group compared to sham group $(\mathrm{P}=0.005)$. $\mathrm{I} / \mathrm{R}$ group animals showed severe mucosal damage, denudation of villi, complete loss of villi and eventually complete mucosal necrosis (median 5 , range 4 - 5) (Figure 1B). Treatment groups I (200 ppm) and II (400 ppm) showed less severe lesions in compared to I/R group, significantly $(\mathrm{P}=0.006, \mathrm{P}=0.008$ respectively). Median and rang of histomorphometric scores in treatment 
groups I and II were recorded $2(1-3)$ and $1(1-2)$ respectively. The results of present study showed that there were significant differences between treatment groups I and II compared to the sham group $(\mathrm{P}=0.005, \mathrm{P}=0.004$ respectively).

Also, the analysis of data demonstrated that there was significant difference between treatment groups I and II (P $=0.054)($ Figure $1 C$ and D).

\section{Discussion}

The results shows that the 0. vulgare leaf ethanolic extracts at doses of 200 and $400 \mathrm{ppm}$ have protective effects against intestinal ischemia-reperfusion injuries in rats. In various organs, including the small intestine, tissue damage and impaired function develop after temporary ischemia; not only during the hypoxic period, but also after re-oxygenation [19]. Blocking the oxygen supply during ischemia of the tissue leads to impeding aerobic energetic metabolism with depletion of intracellular levels of adenosine triphosphate (ATP), disruption of oxidative phosphorylation in the mitochondria and cellular homeostasis [20].

Moreover, there is an accumulation of metabolites, which directly or through mediators can cause cellular injury [21]. Paradoxically, restoration of the blood supply and reintroduction of oxygen to the tissues cause additional cell injury that is referred to as reperfusion injury (oxygen paradox). Oxidative stress, intracellular calcium overload, neutrophil activation and excessive intracellular osmotic load have all been proposed to explain the pathogenesis and the functional consequences of the inflammatory injury that is well documented in the ischemic-reperfused intestine [22]. Compared to other internal organs, the intestine is the organ that is most sensitive to $I / R$ injury in the body [22]. I/R injury of the intestine is a complex, multifactorial, and pathophysiological process that involves the dysfunction of absorption, actions of oxygen-derived free radicals, cytokines, nitric oxide and PMNs [23]. I/R injury to the small intestine causes local production of the ROS, which is known to play an important role in gut epithelial damage [24]. Intestinal mucosal mast cells (IMMC) are particularly frequent in close proximity to epithelial surfaces, where they are strategically located for optimal interaction with the environment and for their putative functions of host defense [25]. Previous studies have demonstrated that the degranulation of IMMC can be induced by oxidants generated in the post-ischemic gut and the released inflammatory mediators such as histamine and tumor necrosis factor- $\alpha$ (TNF- $\alpha$ ) could aggravate the injury to intestine after reperfusion [26, 27]. In line with general $\mathrm{I} / \mathrm{R}$-induced cell damage, also in intestinal I/R, apoptosis is the major mode of cell death in the destruction of epithelial cells [28].

Several agents have been investigated for the prevention and/or treatment of mesenteric $\mathrm{I} / \mathrm{R}$ injury. Agents under investigation include antioxidants, several amino acids, phospholipids, hormones, polyphones and flavonoids, herbal extracts, pharmacological agents, carbon monoxide inhalation, erythropoietin, statins and hyperbaric oxygen $[29,30]$.

In ethnopharmocological knowledge, natural herbal products are studied for development of new drugs with less toxicity and more efficacies [31]. Several herbal therapies containing antioxidant activity have been already suggested for the treatment of intestinal ischemia/reperfusion injuries. Ghasemkhani et al., Kheirandish et al., Abdeen et al. and Campolo et al. in the individual researches administrated Zataria multiflora, olive oil, green tea extract and fenugreek seed extract for protection of intestine tissue following induction of experimental $\mathrm{I} / \mathrm{R}$ injuries, respectively. All of these researches stated that these compounds are able to protect the intestine mucosa against $\mathrm{I} / \mathrm{R}$ injuries mainly via their antioxidant activities [32-35]. O. vulgare is an important medical plant and its antioxidant effect is related to the presence of thymol and carvacrol $[36,37]$. Among the volatile aglycones, besides thymol (3.5\%) and carvacrol $(2.4 \%)$ which are present in relatively small percentage, thymoquinone (40.2\%) as the main component could contribute to the antioxidant activity, even if quinones are generally themselves mild oxiditing agents [38]. Houghton et al. showed the role of thymoquinone as an inhibitor of membrane lipid peroxidation [39]. Flavonoids as the main constituent of O. vulgare extract are a class of plant phenolics with significant antioxidant and chelating properties. Rosmarinic acid another component of $O$. vulgare extract has been reported to have antibacterial, antiviral, antioxidant and antiinflammatory potentials. Rosmarinic acid inhibits the adhesion molecule of PMNs during inflammatory responses, and inhibits the synthesis of eicosanoids and oxidative DNA injury [40].

Srihari et al. have revealed the dose-dependent effecting of $O$. vulgare on lipid peroxidation and antioxidant status in 1, 2-dimethylhydrazine-induced rat colon carcinogenesis [41]; also Emadi et al. have showed protective effect of ethanolic extract of O.vulgare on halothane-induced hepatotoxicity in rats via its antioxidant reliability [17]. The results of this study clearly showed that pretreatment by ethanolic extract of 0 . vulgare (200 and $400 \mathrm{ppm}$ ) had positive effects against intestinal damage resulting from ischemia-reperfusion compared to the $\mathrm{I} / \mathrm{R}$ group in rats. Also intestinal mucosa in treated group by $400 \mathrm{ppm}$ of extract had noticeably less damages in compared to 200 
Table 1. Comparison of Histomorphometric Scores Between Different Groups ${ }^{\mathrm{a}}$

\begin{tabular}{ll}
\hline Groups & Score \\
\hline I/R & $5(4-5)^{\mathrm{A}}$ \\
Sham & $0(0-0)^{\mathrm{B}}$ \\
Treatment I (Origanum, $200 \mathrm{ppm})$ & $2(1-3)^{\mathrm{C}}$ \\
Treatment II (Origanum, 400 ppm) & $2(1-2)^{\mathrm{D}}$ \\
\hline
\end{tabular}

${ }^{\mathrm{a}}$ In each time point, different capital letters in superscript show significant differences between the groups $(\mathrm{P}<0.05)$.

Figure 1. Hematoxylin-Eosin Staining of Intestine of Rats
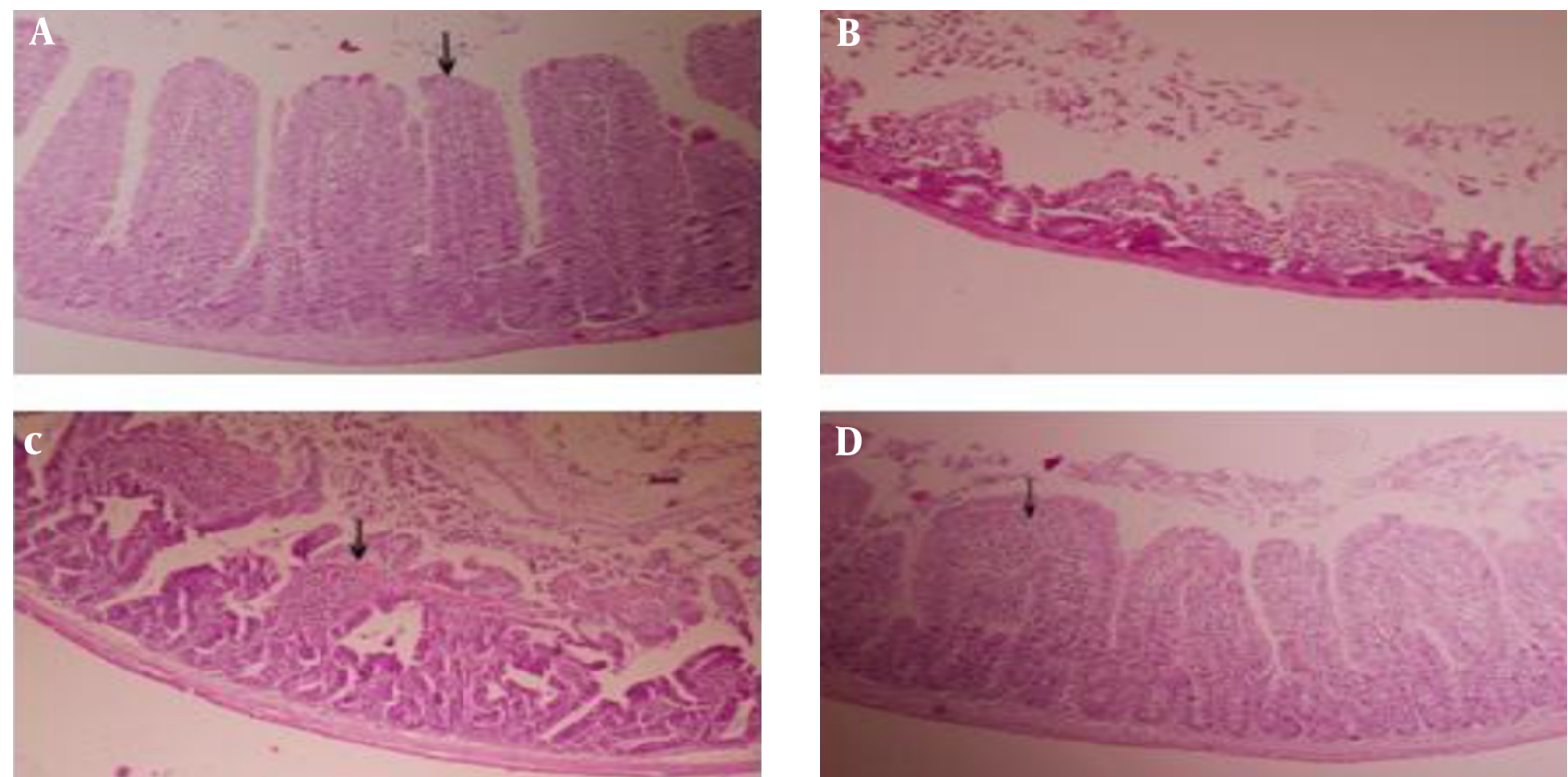

Following experimental ischemia and reperfusion injury by temporary clamping of abdominal aorta, A, normal intestinal mucosal villi (arrow) with normal crypts (Grade 0) in group sham; B, loss of complete villi and crypts and complete mucosal necrosis (Grade 5) in group control; C, fragmentation and loss of upper third of villi (arrow) (Grade 3 ) in group treatment I and D, villous edema and increasing subepithelial space (arrow) (Grade 1) in group treatment II $(100 \times)$.

ppm and this finding revealed that 0 . vulgare extract possess the therapeutic effect in a dose-dependent manner. In conclusion, our study suggested that ethanolic extract of 0 . vulgare has a useful defensive role in the prevention of intestinal $\mathrm{I} / \mathrm{R}$ injuries due to its antioxidant and antiinflammatory properties.

\section{Acknowledgments}

The authors thank the research council of Shahid Bahonar, University of Kerman for supporting this research that is based on the research project belonged to Hamideh Rohani (Number: 420).

\section{Footnotes}

Authors' Contribution: Omid Azari was the project leader. Omid Azari and Reza Kheirandish were responsible for experimental and project design. Omid Azari and Hamideh Rohani performed most of the experiments and statistics analysis. Reza Kheirandish and Hamideh Rohani investigated the pathological slides. Omid Azari and Saeedeh Shojaeepour wrote the manuscript.

Funding/Support: Shahid Bahonar University of Kerman, Kerman, IR Iran.

\section{References}

1. Koike K, Moore FA, Moore EE, Read RA, Carl VS, Banerjee A. Gut ischemia mediates lung injury by a xanthine oxidase-dependent 
neutrophil mechanism. J Surg Res. 1993;54(5):469-73. doi: 10.1006/jsre.1993.1072. [PubMed: 8395621].

2. Collard CD, Gelman S. Pathophysiology, clinical manifestations, and prevention of ischemia-reperfusion injury. Anesthesiology. 2001;94(6):1133-8. [PubMed: 11465607].

3. Moore EE, Moore FA, Franciose RJ, Kim FJ, Biffl WL, Banerjee A. The postischemic gut serves as a priming bed for circulating neutrophils that provoke multiple organ failure.JTrauma. 1994;37(6):8817. [PubMed: 7996599].

4. Swank GM, Deitch EA. Role of the gut in multiple organ failure: bacterial translocation and permeability changes. World J Surg. 1996;20(4):411-7. [PubMed: 8662128].

5. Shirasugi N, Wakabayashi G, Shimazu M, Oshima A, Shito M, Kawachi S, et al. Up-regulation of oxygen-derived free radicals by interleukin-1 in hepatic ischemia/reperfusion injury. Transplantation. 1997;64(10):1398-403. [PubMed: 9392301].

6. Conti CR. Oxygen therapy-use and abuse in acute myocardial infarction patients. Clin Cardiol. 2009;32(9):480-1. doi: 10.1002/clc.20678. [PubMed: 19743491].

7. Vera-Cruz P, Ferreira M, Zagalo C, dos Santos JM, Aguas AP. Structure of the rat nasal mucosa after acute and chronic hyperbaric oxygen therapy. Undersea Hyperb Med. 2010;37(2):125-32. [PubMed: 20462145].

8. Ames JT, Federle MP. CT hypotension complex (shock bowel) is not always due to traumatic hypovolemic shock. AJR Am J Roentgenol. 2009;192(5):W230-5. doi: 10.2214/AJR.08.1474. [PubMed: 19380528].

9. Guo W, Ge D, Wang Q, Xu S, Xue L, Lu C, et al. Diazoxide decreases ischemia-reperfusion injury in a rat model of lung transplantation. Transplant Proc. 2011;43(7):2510-6. doi: 10.1016/j.transproceed.2011.04.015. [PubMed: 21911115].

10. Afarineshe Khaki MR, Pahlavan Y, Sepehri G, Sheibani V, Pahlavan B. Antinociceptive Effect of Aqueous Extract of Origanum vulgare L. in Male Rats: Possible Involvement of the GABAergic System. Iran J Pharm Res. 2013;12(2):407-13. [PubMed: 24250616].

11. Pirigharnaei M, Zare S, Heidary R, Khara J, EmamaliSabzi R, Kheiry F. The essential oils compositions of Iranian oregano (Origanum vulgare L.) populations in field and provenance from Piranshahr district, West Azarbaijan province, Iran.J Food Agric Environ. 2011;9(3,4):89-93.

12. Duke JA. Handbook of medicinal herbs. 2 ed. USA: CRC Press; 2002. p. 243.

13. Matsuura H, Chiji H, Asakawa C, Amano M, Yoshihara T, Mizutani J. DPPH radical scavengers from dried leaves of oregano (Origanum vulgare). Biosci Biotechnol Biochem. 2003;67(11):2311-6. doi: 10.1271/bbb.67.2311. [PubMed: 14646188].

14. Naghibi F, Mosaddegh M, Mohammadi-Motamed S, Ghorbani A. Labiatae family in folk medicine in Iran: From ethnobotany to pharmacology. Iran J Pharm Res. 2005;4(2):63-79.

15. Spiridon I, Colceru S, Anghel N, Teaca CA, Bodirlau R, Armatu A. Antioxidant capacity and total phenolic contents of oregano (Origanum vulgare), lavender (Lavandula angustifolia) and lemon balm (Melissa officinalis) from Romania. Nat Prod Res. 2011;25(17):1657-61. doi: 10.1080/14786419.2010.521502. [PubMed: 21707233].

16. Saeed S, Tariq P. Antibacterial activity of oregano (Origanum vulgare Linn.) against gram positive bacteria. PakJ Pharm Sci. 2009;22(4):4214. [PubMed: 19783523].

17. Emadi L, Azari O, Sakhaee E, Talebian M, Azami E, Shaddel M. Protective effect of ethanolic extract of Origanum vulgare on halothaneinduced hepatotoxicity in rat. Iran J Vet Surg. 2008;3(3):29-37.

18. Chiu CJ, McArdle AH, Brown R, Scott HJ, Gurd FN. Intestinal mucosal lesion in low-flow states. I. A morphological, hemodynamic, and metabolic reappraisal. Arch Surg. 1970;101(4):478-83. [PubMed: 5457245].

19. Gunel E, Caglayan F, Caglayan O, Dilsiz A, Duman S, Aktan M. Treatment of intestinal reperfusion injury using antioxidative agents. J Pediatr Surg. 1998;33(10):1536-9. [PubMed: 9802808].

20. Grace PA. Ischaemia-reperfusion injury. Br J Surg. 1994;81(5):637-47. [PubMed: 8044536].
21. Di Napoli P, Taccardi AA, De Caterina R, Barsotti A. Pathophysiology of ischemia-reperfusion injury: experimental data. Ital Heart J. 2002;3 Suppl 4:24S-8S. [PubMed: 12116822]

22. Granger DN, Hollwarth ME, Parks DA. Ischemia-reperfusion injury: role of oxygen-derived free radicals. Acta Physiol Scand Suppl. 1986;548:47-63. [PubMed: 3529822].

23. Carden DL, Granger DN. Pathophysiology of ischaemia-reperfusion injury. J Pathol. 2000;190(3):255-66. doi: 10.1002/(SICI)10969896(200002)190:3<255::AID-PATH526>3.0.CO;2-6. [PubMed: 10685060].

24. Park PO, Haglund U, Bulkley GB, Falt K. The sequence of development of intestinal tissue injury after strangulation ischemia and reperfusion. Surgery. 1990;107(5):574-80. [PubMed: 2159192].

25. Penissi AB, Rudolph MI, Piezzi RS. Role of mast cells in gastrointestinal mucosal defense. Biocell. 2003;27(2):163-72. [PubMed:14510234].

26. Andoh A, Fujiyama Y, Araki Y, Kimura T, Tsujikawa T, Bamba T. Role of complement activation and mast cell degranulation in the pathogenesis of rapid intestinal ischemia/reperfusion injury in rats. Digestion. 2001;63 Suppl 1:103-7. [PubMed: 11173919].

27. Boros M, Ordogh B, Kaszaki J, Nagy S. The role of mast cell degranulation in ischaemia-reperfusion-induced mucosal injury in the small intestine. Ann Acad Med Singapore. 1999;28(1):79-84. [PubMed: 10374030].

28. Ikeda H, Suzuki Y, Suzuki M, Koike M, Tamura J, Tong J, et al. Apoptosis is a major mode of cell death caused by ischaemia and ischaemia/reperfusion injury to the rat intestinal epithelium. Gut. 1998;42(4):530-7. [PubMed: 9616316].

29. Martinez JP, Hogan GJ. Mesenteric ischemia. Emerg Med Clin North Am. 2004;22(4):909-28. doi: 10.1016/j.emc.2004.05.002. [PubMed: 15474776].

30. Chatterjee PK. Novel pharmacological approaches to the treatment of renal ischemia-reperfusion injury: a comprehensive review. Naunyn Schmiedebergs Arch Pharmacol. 2007;376(1-2):1-43. doi: 10.1007/s00210-007-0183-5. [PubMed: 18038125].

31. Borrelli F, Izzo AA. The plant kingdom as a source of anti-ulcer remedies. Phytother Res. 2000;14(8):581-91. [PubMed: 11113992].

32. Ghasemkhani N, Azari O, Kheirandish R. Effect of Zataria multiflora boiss on experimental intestinal ischemia-reperfusion injury in male Wistar rats. Online J Vet Res. 2013;17(12):638-44.

33. Kheirandish R, Azari O, Samadieh H, Rasa Z. Protective effect of trigonella foenum graecum (fenugreek) seed extract on experimental intestinal ischemia/reperfusion injury in rats. Iranian J Vet Surg. 2013;6(1):37-46.

34. Abdeen SM, Mathew TC, Dashti HM, Asfar S. Protective effects of green tea on intestinal ischemia-reperfusion injury. Nutrition. 2011;27(5):598-603. doi:10.1016/j.nut.2010.05.014. [PubMed: 21167681].

35. Campolo M, Di Paola R, Impellizzeri D, Crupi R, Morittu VM, Procopio A, et al. Effects of a polyphenol present in olive oil, oleuropein aglycone, in a murine model of intestinal ischemia/reperfusion injury. J Leukoc Biol. 2013;93(2):277-87. doi: 10.1189/jlb.0712317. [PubMed: 23233730].

36. Milos M, Mastelic J, Jerkovic I, Katalinic V. Chemical composition and antioxidant activity of the essential oil of oregano(Origanum vulgare L.) grown wild in Croatia. Italian magazine EPPOS. 2000:616-24.

37. Yanishlieva NV, Marinova EM, Gordon MH, Raneva VG. Antioxidant activity and mechanism of action of thymol and carvacrol in two lipid systems. Food Chem. 1999;64(1):59-66.

38. Guenther E, Althausen D. The essential oils. Toronto: D. Van Nostrand Press; 1963. p. 555.

39. Houghton PJ, Zarka R, de las Heras B, Hoult JR. Fixed oil of Nigella sativa and derived thymoquinone inhibit eicosanoid generation in leukocytes and membrane lipid peroxidation. Planta Med. 1995;61(1):33-6. doi: 10.1055/s-2006-957994. [PubMed: 7700988].

40. Sahin F, Gulluce M, Daferera D, Sokmen A, Sokmen M, Polissiou M, et al. Biological activities of the essential oils and methanol extract 
of Origanum vulgare ssp. vulgare in the Eastern Anatolia region of Turkey. Food Control. 2004;15(7):549-57.

41. Srihari T, Sengottuvelan M, Nalini N. Dose-dependent effect of oregano (Origanum vulgare L.) on lipid peroxidation and antioxi- dant status in 1,2-dimethylhydrazine-induced rat colon carcinogenesis.J Pharm Pharmacol. 2008;60(6):787-94. doi: 10.1211/jpp.60.6.0015. [PubMed: 18498716]. 